\title{
SOCIOLOGY OF KNOWLEDGE AND QUALITATIVE METHODOLOGY*
}

\author{
Dexter Bryan \\ California State College, Dominguez Hills
}

The antagonism between the sociology of knowledge and standard research methods is examined in terms of the contemporary analysis of blue-collar workers. Qualitative methodology is suggested as a possible alternative to the historical research orientation that has dominated the sociology of knowledge. Conceptual and methodological suggestions designed to merge sociology of knowledge interests with qualitative methodology are offered with empirical examples drawn from a participant observation study of steel workers.

The sociology of knowledge is rich in theory. It spans Durkheim's dualistic theory of knowledge to Marxian dialectics. Contemporary sociologists have not linked these complex theories about existence and consciousness to a methodology sensitive to complex relations between social structure and thought. Consequently, there has been very little empirical work in the sociology of knowledge. ${ }^{1}$

Empirical work is inhibited by the frustration experienced by those who have tried to use standard research methods for doing sociology of knowledge projects. Most methods are one-sided, that is, they focus on social organization or consciousness, but not on the relations between social structure and thought. In depth interviews, for example, are excellent for studying psychological mechanisms and personal biographies, but, as Robert Lane (1962) notes, they tell little about how political, economic, educational, and religious institutions--the "existential base"-affect the political ideology of one's subjects.

The antagonism between standard research methods and sociology of knowledge orientations can be seen in the recent attempts to explain the consciousness of the blue collar worker. James Reinhart (1970) finds two dominant images of the "new worker" in the contemporary sociological literature, both of which reflect specific methodological orientations. One image of the worker emerges from survey and fixed-choice questionnaires. Based upon abstract categories which project a liberal academic orientation, these methods produce a view of the working class as a "homogeneous mass whose most prominant characteristics are racism, authoritarianism, and non-commitment to the norms of democracy." The other image rests upon a comparison of the old and new working class. The Embourgeoisement theoriets explain away class consciousness and radical spirit by focusing on improved conditions and the affluence of the "new working class." Their method offers the image of the vanishing worker or non-worker, a new blue collar type who is joining his white-collar neighbors in the "middle-mass."

Rinehart claims that both of these images are false. They dismiss or distort the radical potential of workers and leave the sociologist "defenseless and surprised" when a concrete labor struggle breaks out, as for example, the violent strike at the Vauxhall plant which emerged even before Goldthorpe and his associates could publish the third volume of The Affluent Worker. The important point here is 
that the limitations of these images must be seen in light of the one-sided methods which produced them. The survey researchers separate the world view of the workers from its context and organize it into reified categories. By abstacting "attitudes," they ignore structure and produce a static view of the worker. The Embourgeoisement theorists, on the other hand, offer a 1imited structural analysis. The workers' social position as worker is nullified when his income is compared to that of his grandfather. More important, the Embourgeoisement theorists assume that affluence will automatically produce a change in working class consciousness. Both methods thus loose the sense of a situated radical potential and project a generalized conservatism.

Both methods, especially survey research, ignore and thereby cannot explain what is most salient to understanding the worker--the social world of work and its temporal but constant influence on thinking. In dismissing the influence of the work scene, they are like other research strategies which begin to explain consciousness by first separating it from the social relations in which it is produced and maintained. Survey research systematically captures consciousness from practice. It turns consciousness into a historical phenomenon. It imposes an organization on the logic used to handle everyday affairs by shaping beliefs and attitudes into standardized dimensions. This is antagonistic to the sociology of knowledge, a discipline which is interested in the form as well as the content of knowledge. As Danziger (1963) notes, standard survey methods make men reactors to and not creators of knowledge.

Once separated from their context, aggregates of attitudes acquired in "professional" interview settings may not be easily correlated with structural variables. Only intense and clearly felt beliefs can be easily correlated with class and ethnicity. It is less clear how occupying a social position affects, in the case of Rinehart's workers, radicalization of one's world view. As early as 1944, Child argued that it is only possible to impute an ideology to "affiliation groups" who consciously produce and maintain ideological positions. The interest of affiliation groups is clearly seen in their activities, while the beliefs of the masses, with their more vague modes of thought, are not easily tied or correlated to social structure variables and are thereby excluded from analysis.

As the inflexibility of correlational logic places limits on the subject matter in empirical sociology of knowledge, the antagonism between survey research and sociology of knowledge reinforces the notion that a true sociology of knowledge analysis must be historical. Gouldner's (1965) study of ancient Greece is more likely to be considered an appropriate sociology of knowledge thesis than is Leggett's (1968) research on class consciousness in Detroit. Largely because of an inadequate methodology, the sociology of knowledge escapes into the past, leaving contemporary problems to social psychologists and students of formal organization.

If the sociology of knowledge is to deal with the present, superimposed statistical analysis must be replaced with a methodology sensitive to the multifarious influences that social systems can have on world view. Correlational analysis must give way to the study of social processes. There must be a change in research goals. Instead of focusing on the statistical significance of the correlation between structural variables and abstracted attitudes, one must look for and document the ways social processes affect thinking. A methodology is needed which enables the researcher to locate thinking in social action. First, the social scientist must be in a position to describe and conceptualize the subject's world view. Instead of abstracting individual dimensions of thought, the researcher must penetrate the subjects world to observe the integration of the whole, that is, what 
is salient and repetitious in the subject's thinking, how he presents himself in normal social encounters, and how he organizes and compartmentalizes his beliefs.

Second, one must be able to describe the composition and boundaries of the actor's social world. The actor cannot be understood solely in terms of his conscious existence, that is, learning the subject's language is not sufficient. In order to offer an explanation of consciousness we must go beyond the description of "meaning," and determine instead how social situation affects perspective and world view. One begins to transcend the naturalistic perspective of the actor by creating a picture of the roles and positions which encompass his social world.

All of this points to qualitative methodology. Participant observation provides in-depth analysis of the actor's system of meanings, focuses on the operation of social systems over time, and, most important, grounds the subject's beliefs in the makeup of his social group or community. Yet students of qualitative methodology have not been interested in the question of how social systems affect thinking. They have left an explanation of consciousness to others and have limited their analysis to understanding subjective meaning and the symbolic superstructure which make up a particular shared "reality." Bruyn (1966) for example, distinguishes between interpretative and empirical statistical knowledge. In keeping with Weber, he relinquishes causal explanation to the latter and limits participant observation to the analysis of "human" facts.

Bruyn's division of sociological labor is evident in Cicourel's (1964) insightful discussion of qualitative methodology. Cicourel argues that the methodological problems of the participant observer involve the ambivalence between simultaneously attending to both the rules used by the actor to govern his everyday affairs and the researchers theoretical constructs. With an appropriate means of communication, the researcher could develop a community (of meaning) with the actor. Since the problem is defined as a problem of meaning, Cicourel suggests that the sociologist study the logic of commonsense meanings. Cicourel notes the necessity of the participant observer in assuming an analytic role. Yet he envisions the participant observer more as a translator of "meaning" than a critical analyst seeking a sociological explanation of meaning. While survey research uses statistics to create relations between structure and consciousness, qualitative methodology tends to ignore the problem of relations and limits itself to the phenomenological description and internal analysis of consciousness. Paradoxically, the research orientations required for a non-historical sociology of knowledge of knowledge are found in a methodological tradition which has little theoretical interest in the sociology of knowledge.

Some participant observation studies have bordered on the sociology of knowledge. Becker's (1961) study, for example, shows how the perspective and value orientation of medical students change during their occupational socialization. Skolnick, in his 1967 study of the police, shows how social structure affects the policeman's working personality. By associating social marginality with an attitude structure and presentation of self, Skolnick relates social structure to consciousness. Yet qualitative methodology can be more useful to the sociology of knowledge. Much has been written about what to record, how to record, the ambivalence of the participant-observer role, how to get in, stay in and get out. Little concern has been directed toward how to make explanatory inferences. The problem of validating qualitative data, one's understanding of the actor, has received a great deal of attention. Documenting one's "hunches" that go beyond the actor's self-concept to an explanation of his world view has been neglected. 
Some rudimentary theoretical and methodological suggestions are offered here in order to bring the sociology of knowledge and qualitative methodology in closer accord. Since the blue collar worker has been used to show the antagonism between the sociology of knowledge and both correlational analysis and survey research, it is appropriate to clarify these suggestions with examples from a participant observation study of steel workers. The study was based upon job observations and interviews with approximately fifty open-hearth workers.

The standard participant observation study and a sociology of knowledge design would differ initially in terms of their focus on and assumptions about the actor. The typical participant observer makes the actor or group the object of his research and analysis. One interested in sociology of knowledge would treat the actor as a reflection of something else; he would look beyond the actor to the system of which he is a part, including its effect on him. The main point of Rinehart's critique is that the consciousness of the worker cannot be treated as independent of his world, that is, he must be seen in the light of the social relations in which he exists.

If Rinehart followed the sociology of knowledge, he would next determine how self image and political thoughts reflect the operation of this social system. Political apathy and harmonious attitudes toward job and management may reflect, for example, the stability of economic times, a strong new contract, an open plant mobility system, or a liberal management strategy. Yet a structural change might in a short time alter attitudes. For example, among steel workers in this study, the sense of powerlessness and anti-management feelings intensified when a high level management decision concerning a major new piece of equipment changed the incentive program. During the boom period of the early sixties, which was characterized by an open straight tonnage incentive program, the steel plant was a good place to be. As one respondent put it "In those days, it was something to be a steelworker." The new "caster" and a resulting standardization of incentives led to a negative conception of the job, talk of wildcating, a tendency to develop escape plans, and a general reluctance to persuade friends and family to work at the plant.

A sociology of knowledge analysis could not, however, depend solely on inferences drawn from social change. Like all sociological endeavors, the main focus must be on the impact of regular social encounters and routine status systems. In the steel plant, for example, there is a strong parallel between the formal stratification system and the workers' vocabulary of motive. Most of the open-hearth workers said they transferred to that department for the better income, irrespective of the job, heat and danger. When asked about their work, most subjects defined their jobs in terms of the money or "points." Likewise, the formal role relations and informal social distance between management and labor leaves little room for the steel worker to develop an unrealistic conception of where he stands. The union "Brothers" know where the bosses park, who is a company man and which bars belong to them.

It is relatively easy to show continuities between occupational structures and attitudes which are tied to membership in those structures. This would be the first step in analysis. It may be true that the mainstream of the workers' consciousness revolves around the issue of industrial conflict and not, as Lipset would have us believe, the political party system. Yet a sociology of knowledge orientation ultimately leads to questions about world view or Weltanschauung. One must see if and how social life leads to an interpretation of larger social and political issues that originate outside of the home base. Steel workers, for example, lost interest in wage and price controls once they found out that their 
new contract was safe. The pressures of manual labor and weekly shift changes seem to reinforce the white workers negative political attitudes towards both big business and welfare recipients. The threat of a competing Japanese steel market and the dislike of foreign import cars have an affinity with a negative attitude toward foreign aid and a policy of isolationism. The Japanese market makes the men pro-American and yet, because they feel that American steel companies have a piece of the foreign action, the workers are anti-big business. To them this double involvement of American money at home and abroad is another case of "socialism for the rich and capitalism for the poor." The tendency to generalize work experience to a larger world view is seen among a significant minority of workers, mostly the young, who extend their feelings of powerlessness on the job to the larger political arena and, consequently, do not vote.

Pointing to the relation between life style and thought is not the same as showing how interview data are limited to time and place. Instead of isolating attitudes and beliefs from "extraneous variables," those reasons which show that men are not non-reacting constructs should be emphasized. While a conception of the actor's real life situation is the research goal, the logic of the ideal type can be used to over exaggerage the effects of single or specific combinations of variables. The ideal type lends itself to theoretical explanation by creating "if than" or "what if" hypotheses. Methodologically, this sensitizes the researcher to the actual situation. It makes sense, for example, to begin the analysis of a steel mill by examining what the steel worker would be like if he lived in a traditional occupational community, geographically narrow, with its own communication system and leadership roles.

The socialization process is not just a question of how the actor acquires a social position, but how the process or system continues to act upon the individual. Sometimes the subject is offered a ready made world view. It is more likely that his self-concept is latent in the learning and performing of normal roles. The question here is how much pressure does the system put on the actor? Does the degree of structural cohesiveness inhibit the possibility of developing alternative conceptions of self? The question "could a steel worker be pro-management" was simply ludicrous to most of the workers. From the first day on the job, the pub1ic display of status distinctions draws the worker toward his fellows. The management has different bathroom facilities, works regular hours, wears a different uniform, gets stock options, and attends special meetings and social gatherings which exclude workers. This social process is reinforced by active union recruitment and informal social encounters among the men. One union official told how he always tries to talk to the new men, to tell them about the union and their rights. The new men learn about the custom of stopping in for "breakfast" at the local bar after their first graveyard shift. It seems impossible to be cognitively neutral in the steel mill. While the men feel that the management's position is legitimate they are also aware of the pervasive management-labor split. Perhaps more significant than the animosity towards management is the deference paid to the company. The competition the workers face in the social relations of production seems natural to them; it never allows them to develop radical conceptions of ownership and control of the plant. The few radical workers did not acquire their beliefs from the job or union. While the men in the open-hearth can "fill your ear with the management," most of them say they understand the position of the management and would do the same thing if they were in the bosses' shoes.

A theoretical interest in how stable and changing social arrangements and socialization affect self concept and world view says nothing of how one can make reliable inferences from participant observation data. A comparison between the novice worker and "old timer" is the first important methodological basis for 
validating explanatory inferences. The effect of the mill on the men and their attitudes can be seen in a comparison of older and new workers. In the steel mil1, "greenhorns" must go through a three month trial period. Proving themselves as trustworthy to the crew is the first step in being accepted, becoming an oven man. The very new workers tend to be marginally involved in the union. They are usually not married and spend most of their leisure time partying. 01d timers say that it is when the young man gets married and gets a better job that he becomes "responsible" and a good union man. One of the union leaders has a "theory" which outlines the steps by which apathetic or overzealous workers become solid grievance men. After the initial breaking-in period, the new man begins to learn how to "talk steel." Some of the young workers tell jokes about how the older men talk steel to their wives at night.

Analytic comparisons can be extended to subjects who occupy different social positions. It is very important to find out what happens in upward and downward social mobility. Conversations with and about the "melters" or line foremen substantiate the salience of class distinctions in the steel mill. To the men on the floor, the transition from worker to lower level management involves a shift in loyalties and a complete change in their way of thinking, something strong union men cannot do.

What happens to the participant observer, how he is defined and treated, can also be a basis for developing and confirming explanations of consciousness. The traditional interest in legitimating one's presence and developing rapport should be combined with an analysis of the social systems and processes which inhibit or enhance ones arrival, that is, getting in should be an analytic not simply a pragmatic endeavor. This is what Cicourel (1964) means when he argues that the actual research situation is an important source of data. A participant observation study that conceptualizes and developes a "natural history" can use the observers experiences, particularly the changes in his perspective, to make inferences about social structure. During the first days in the mill, the workers avoided the researcher. They thought he was a management spy or trainee, someone who could not be trusted. Reassuring the men of non-involvement with management was not enough to attain entry into the workers' subculture. A marginal but legitimate status was acquired over time by going to bars and shoveling in the furnace with the men. After going through the process of being accepted by union officials and the men, it is unlikely that one could believe that the worker and labor-management conflict is disappearing.

Another way to check inferences is to observe presentations of self as the actor enters into and exits from his social world. Shifts in presentation reflect the actor's attempt to deal with structural divisions in his world. Thus, the affects of social organization can be seen by observing how the self is manipulated in varlous situations. The noise level in the open-hearth inhibits lengthy conversations and the telling of jokes. The men pantomime and act out their emotions. Of course this performance stops when management comes on the floor. This is not so much because foking is a threat to production, but that it is something private among the men. Labor-management relations are formal, bound up in their contract. Workers who are not directly involved with management, treat the bosses as if they were not present.

In summary, these theoretical and methodological suggestions imply that the sociology of knowledge would: 
1. extend qualitative methodology beyond description and analysis of the actors conscious existence by seeking parallels between social organization and the organization of thought in stable and changing social institutions;

2. attempt to relate the everyday experiences of the actor in his subculture or "home base" to his larger world view;

3. make use of socialization, analytic comparisons, the actors presentation of self and the observers experiences to make inferences.

More sophisticated methodological strategies will develop - when sociologists focus directly on relations between social structure and consciousness instead of employing statistics to make second-hand inferences. The real task is to create this methodology without implying a solution to the problem of determinism. Too many studies begin with premature assumptions about human freedom, only to end as empirical exercises trapped in their own imagery. The methodology conceptualized here must allow the researcher to supply appropriate political and theoretical orientations, to focus on reference groups or exploitation. Yet any social system must be initially conceptualized as a network of social relations which may be tightly or loosely woven, that is, it is the research task to map out how social systems do affect thinking. The worker's "false consciousness," for example, must be explained not rationalized. The problem of human freedom must be transformed from a matter of theoretical speculation to a question of empirical evidence.

Specific methodological procedures must be developed without separating consciousness from practice and without reifying concepts like cohesion and pervasiveness into scalable and neutral dimensions. This is basic to both qualitative methods and the sociology of knowledge. Bringing the two together may help update the sociology of knowledge and expand the uses of participant observation. If a "description from inside" can assist a sociologist in discovering a working class consciousness and a radical potential among workers, other sociologists may also begin to discover the situated sources of political mentality. Most important, this approach may encourage more sociologists to study social systems, rather than psychological variables.

\section{Footnotes}

*A paper presented in the Qualitative Methodology section of the 1972 Pacific Sociological Association Meetings.

$1_{\text {Note the lack of empirical studies found in the sociology of knowledge readers }}$ and textbooks. See James F. Curtis and John W. Petras, 1970.

\section{References}

Becker, Howard S.

1961 Boys in White. Chicago: Chicago University Press.

Bruyn, Severyn

1966 The Human Perspective in Sociology. Englewood Cliffs: Prentice-Hall.

Child, Arthur

1944 "The problem of imputation resolved." Ethics Liv (January):96-109. 


\section{Cicourel, Aaron}

1964 Method and Measurement in Soclology. New York: Free Press.

Danziger, $\mathrm{K}$.

1963 "Ideology and utopia in South Africa: A methodological contribution to the sociology of knowledge." British Journal of Sociology 14:59-76.

Gouldner, Alvin

1965 Enter P1ato. New York: Basic Books.

Lane, Robert

1962 Political Ideology. New York: Free Press.

Leggett, John C.

1968 Class, Race, and Labor. New York: Oxford.

Reinhart, James W., and Seymour Farber

1970 "Structural sources of working class political unrest." Paper presented at the annual meeting of the Society for the Study of Social Problems. Washington, D.C.

Skolnick, Jerome

1966 Justice Without Trial. New York: Wiley. 